e-ISSN: 2721-9038

p-ISSN: 2721-902X

\title{
PENGGUNAAN MEDIA E-LEARNING EDMODO UNTUK MENINGKATKAN KEMAMPUAN BERPIKIR KRITIS PESERTA DIDIK
}

\author{
Eminari Simatupang ${ }^{* 1}$, Ratih Permana Sari ${ }^{2}$, Nurhafidhah ${ }^{3}$ \\ ${ }^{1,2,3}$ Program Studi Pendidikan Kimia, FKIP Universitas Samudra \\ Jln. Kampus Meurandeh, Langsa 24416 \\ *Email: eminarisiburian@gmail.com
}

\begin{abstract}
Abstrak
Kemampuan berpikir kritis peserta didik yang rendah adalah masalah yang masih umum di dunia pendidikan. Penelitian ini bertujuan untuk mengetahui peningkatan kemampuan berpikir kritis peserta didik setelah penggunaan Edmodo sebagai media e-learning. Metode yang digunakan dalam penelitian ini adalah metode kuantitatif dengan jenis penelitian eksperimen One Group Pretest-Posttest Design. Populasi dalam penelitian ini adalah seluruh peserta didik kelas XI IPA SMA Negeri 4 Langsa. Sampel dalam penelitian ini adalah kelas XI IPA-1 SMA Negeri 4 Langsa tahun ajaran 2020/2021 yang terdiri dari 21 orang yang dipilih secara purposive sampling. Instrumen yang digunakan dalam penelitian ini adalah tes kemampuan berpikir kritis. Hasil penelitian menunjukkan bahwa Kemampuan berpikir kritis peserta didik mengalami peningkatan yang signifikan setelah dengan $\mathrm{N}$-Gain 0,55 (kategori sedang), nilai mutlak t hitung yang diperoleh pada uji hipotesis lebih besar dari t tabel $(10,41>1,64)$. Guru Kimia diharapkan dapat menggunakan Edmodo sebagai media e-learning secara khusus pada materi pembelajaran yang perlu divisualisasikan, karena Edmodo memiliki fitur yang mendukung kegiatan tersebut.
\end{abstract}

Kata Kunci: $\boldsymbol{e}$-learning, Edmodo, kemampuan berpikir kritis.

\begin{abstract}
The low critical thinking ability of students is a problem that is still common in the world of education. This study purposed to determine the improvement of students' critical thinking skills after using Edmodo media. The method used in this study is a quantitative method with the type of experimental research One Group Pretest-Posttest Design. The population in this study were all students of class XI IPA SMA Negeri 4 Langsa. The sample in this study was class XI IPA-1 SMA Negeri 4 Langsa school year 2020/2021 which consisted of 21 people who were selected by purposive sampling. The instruments used in this research is critical thinking ability test. The critical thinking ability of students has increased significantly after the N-Gain 0.55 (medium category), the t test value obtained in the hypothesis test is greater than the table (10,41 > 1.64). Chemistry teachers are expected to be able to use Edmodo as an e-learning medium specifically on learning materials that need to be visualized, because Edmodo has features that support these activities.
\end{abstract}

Key word: e-learning, Edmodo, critical thinking ability 
e-ISSN: 2721-9038

p-ISSN: 2721-902X

\section{PENDAHULUAN}

Revolusi industri 4.0 merupakan era pengoptimalan teknologi cyber otomatisasi proses pengerjaan diberbagai bidang. Ini merupakan tren otomatisasi dan pertukaran data dalam teknologi manufaktur. Industri 4.0 identik dengan dunia virtual. Artinya seluruh kegiatan sosial, ekonomi, dan industrial akan lebih banyak memanfaatkan teknologi jaringan internet daripada tenaga fisik manusia. Untuk itulah pendidikan indonesia dituntut untuk menghasilkan SDM yang memiliki keterampilan abad 21, salah satunya adalah kemampuan berpikir kritis (Rohman, 2018).

Berdasarkan data dari Programme For International Student Assessment (PIZA), rendahnya kemampuan berpikir kritis peserta didik adalah masalah yang masih sangat umum di dunia pendidikan. Kemampuan berpikir kritis di Indonesia masih sangat rendah, hal tersebut dibuktikan bahwa Indonesia memperoleh skor 397 dan menduduki urutan ke-62 dengan total peserta 72 negara (Nuzul, 2019).

Zainuddin dan Pambudi (2019) pada penelitiannya menyatakan bahwa keterampilan berpikir kritis pada pretest dan posttest mengalami peningkatan yang signifikan yaitu Ngain 0,6 kategori sedang. Dimana indikator berpikir kritis yang diterapkan adalah kemampuan mengidentifikasi masalah, memecahkan masalah dan membuat kesimpulan. Berdasarkan permasalahan tersebut, maka penulis tertarik untuk meneliti lebih lanjut tentang penggunaan media elearning Edmodo untuk meningkatkan kemampuan berpikir kritis peserta didik pada pembelajaran kimia.
Edmodo adalah perusahaan teknologi pendidikan yang menawarkan alat komunikasi, kolaborasi dan pembinaan untuk guru dan sekolah. Edmodo merupakan sebuah platform microbogging pribadi yang dikembangkan untuk guru dan peserta didik dengan mengutamakan privasi peserta didik. Guru dan peserta didik dapat berbagi catatan, tautan dan dokumen. Guru juga memiliki kemampuan untuk berbagi konten, mendistribusikan kuis, tugas, dan mengelola komunikasi dengan peserta didik, kolega, dan orangtua peserta didik (Karimah dkk, 2018).

Edmodo adalah sebuah platform web dengan menggunakan konsep sosial networking berbasis microbloging yang dikhususkan untuk membangun lingkungan besar online yang aman untuk berbagi data, informasi, serta konten-konten pendidikan baik berupa tulisan, dokumen, video, audio, foto ataupun link yang dapat dibagikan oleh guru maupun peserta didik dan juga konten khusus berupa nilai, kuis, acara kegiatan, penugasan dan polling yang hanya dapat dibagikan oleh guru (Karimah dkk, 2018). Edmodo menyediakan beberapa fitur diantaranya yaitu File and links, Assignment, Quiz, Gradebook, Polling, Library, dan Parent Code (Yuniarti dan Ifadah, 2018).

Edmodo memiliki beberapa kelebihan diantaranya (Karimah dkk, 2018): (1) User interface: dengan mengadaptasi tampilan Facebook secara sederhana Edmodo relatif mudah untuk digunakan. (2) Compatibility: Edmodo mendukung berbagai jenis format file. (3) Edmodo tidak hanya diakses menggunakan PC tetapi juga dapat diakses menggunakan ponsel pintar berbasis android OS. (4) Menyediakan 
fitur untuk membuat grup diskusi kelompok. (5) Pesan dirancang untuk lebih mudah dipahami dan tidak dibatasi oleh jumlah karakter.

Berpikir kritis merupakan sebuah proses terstruktur dimana seseorang dapat merefleksikan diri untuk menimbang setiap keyakinan dan pendapat berdasarkan bukti maupun asumsi yang logis. Pertimbangan muncul karena adanya kemampuan untuk memahami, mengingat, menafsirkan, mencari adanya hubungan, serta mengevaluasi bahkan membuat hipotesis (Hendriana, 2017).

Seseorang yang berpikir kritis mampu melihat persoalan dari berbagai sudut pandang, terbuka terhadap hal-hal baru sekalipun dianggap kurang masuk akal, tidak mudah menerima argumen yang belum terbukti benar, tidak emosional, membuat kesimpulan dan keputusan berdasarkan fakta, serta mampu memecahkan masalah. Critical thingking menurut Zakiah (2019) merupakan istilah umum untuk berbagai kemampuan kognitif dan intelektual seperti: (1) Kemampuan mengidentifikasi, menganalisis, serta mengevaluasi secara efektif; (2) Menentukan dan mengatasi prasangka; (3) Merumuskan dan menyajikan alasan-alasan yang meyakinkan untuk mendukung kesimpulan; (4) Membuat pilihan yang cerdas dan beralasan tentang apa yang harus dipercaya dan yang harus dilakukan.

Seseorang yang memiliki kemampuan berpikir kritis memiliki sifat yang teliti, memiliki standarisasi pengambilan keputusan yang didasari relevansi, pertimbangan yang matang, dan berusaha untuk memberi solusi terbaik untuk setiap persoalan. Kemampuan berpikir kritis memiliki beberapa indikator, diantaranya: (1) Memfokuskan pertanyaan, Menganalisis argument, (2) Menjawab pertanyaan tentang suatu penjelasan, (3) Mempertimbangkan apakah sumber dapat dipercaya atau tidak, (4) Mengamati dan mempertimbangkan suatu laporan hasil observasi, (5) Menentukan tindakan, (6) Mendeduksi dan mempertimbangkan hasil deduksi, dan (7) Menginduksi dan mempertimbangkan hasil induksi (Khoirunnisa, 2020).

\section{METODOLOGI PENELITIAN}

Penelitian ini dilaksanakan di SMA Negeri 4 Langsa tahun ajaran 2020/2021. Waktu pelaksanaan penelitian ini dimulai pada bulan Februari sampai dengan Mei 2021. Populasi dalam penelitian ini adalah seluruh peserta didik kelas XI IPA di SMA Negeri 4 Langsa tahun pelajaran 2020/2021 yang berjumlah 41 orang. Dalam teknik pengambilan sampel secara purposive, Dalam penelitian ini, yang menjadi sampel adalah peserta didik di kelas XI IPA-1 SMA N 4 Langsa dengan jumlah 21 orang.

Penelitian ini menggunakan pendekatan kuantitatif dengan menggunakan penelitian eksperimen semu dengan jenis one group pretestposttest design. Tahapan penelitian adalah tingkatan atau jenjang dalam proses penelitian. Tingkatan-tingkatan tersebut direncanakan, kemudian dilakukan secara terstruktur, logis, dan sistematis. Tahapan penelitian dapat dilihat pada gambar berikut: 
e-ISSN: 2721-9038

p-ISSN: 2721-902X

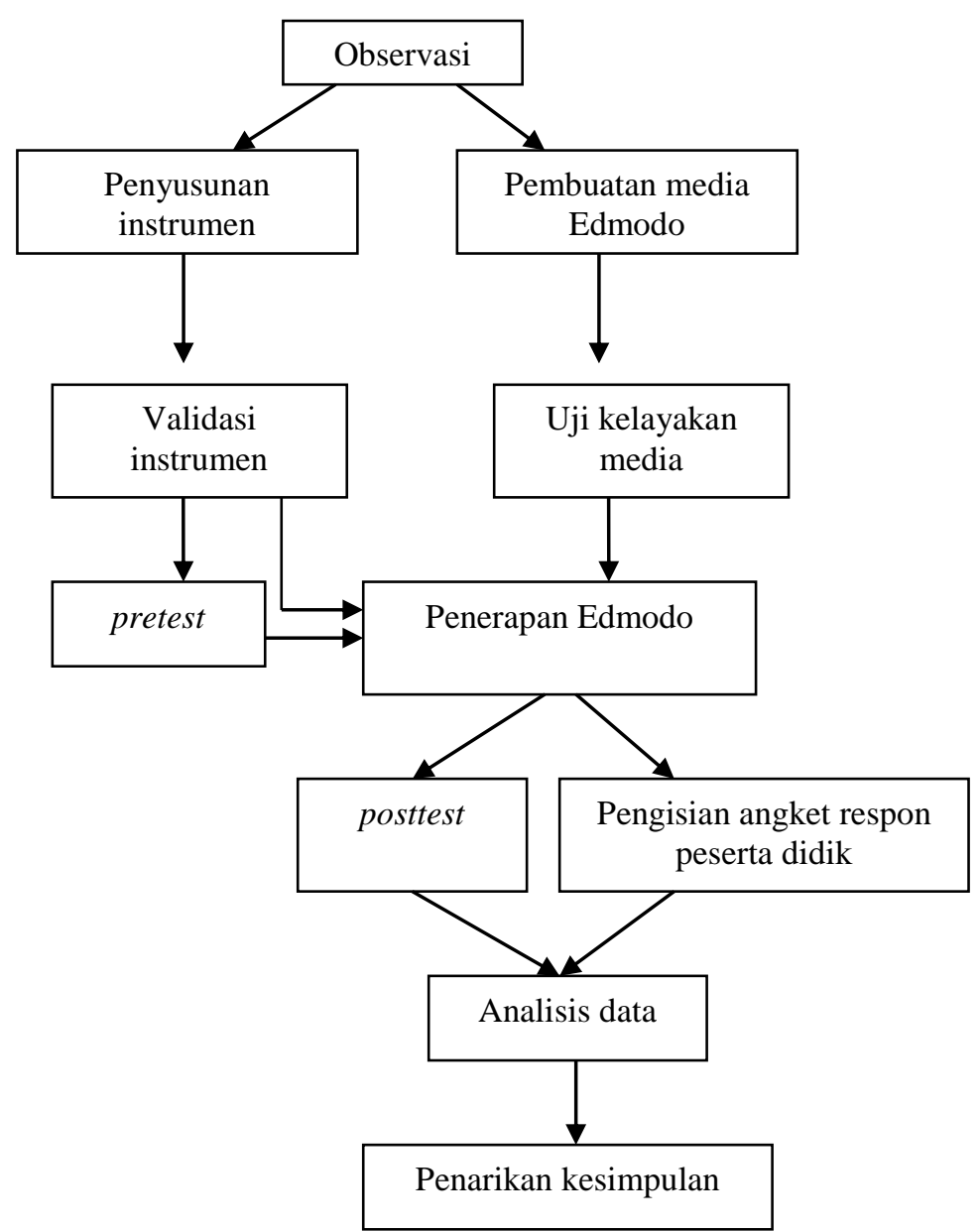

Gambar 1. Tahapan pelaksanaan penelitian

Teknik pengumpulan data dalam penelitian ini adalah menggunakan soal tes kemampuan berpikir kritis dalam bentuk pilihan berganda. Sebelum instrumen digunakan, terlebih dahulu divalidasi oleh ahli. Soal berpikir kritis diuji validasi primer menggunakan rumus poin biserial dengan persamaan berikut (Sugiyono, 2018), kemudian dihitung reliabilitas dengan rumus Kuder Richatson (Lestari, 2017), selanjutnya dihitung tarah kesukaran dan daya pembeda soal dengan persamaan yang sesuai dengan bentuk soal pilihan berganda (Sugiyono, 2018),

Untuk memperoleh nilai kemampuan berpikir kritis peserta didik, pertama dilakukan penskoran terhadap tiap-tiap butir soal lalu dihitung dengan rumus penetapan nilai pretest dan posttest berikut (Lestari, 2017):

Gain normal dihitung untuk mengetahui perbedaan (peningkatan atau penurunan) antara hasil pretest dan posttest setelah adanya perlakuan. Perhitungan gain normal menurut Lestari (2017), dapat dilakukan menggunakan persamaan berikut:

$$
g=\frac{s_{\text {post }}-s_{\text {pre }}}{s_{\text {max }}-s_{\text {pre }}}
$$

Keterangan :

g : gain normal

$\mathrm{s}_{\text {post }} \quad$ : skor posttest

$\mathrm{S}_{\text {pre }} \quad$ : skor pretest

$\mathrm{s}_{\max } \quad$ : skor maksimal 
Menurut Fajiyusny (2017), persentase ketercapaian indikator kemampuan berpikir kritis dihitung dengan menjumlahkan skor yang diperoleh seluruh peserta didik pada setiap indikator dengan menggunakan rumus persentase.

Sebelum dilakukan pengujian hipotesis, harus dilakukan uji normalitas data terlebih dahulu karena syarat untuk menguji hipotesis adalah data yang hendak diuji harus berdistribusi normal. Menurut Lestari (2017), normalitas dapat dihitung dengan menggunakan rumus chi kuadrat yang ditulis dalam persamaan matematis berikut:

$$
x^{2}=\sum \frac{\left(O_{i}-E_{i}\right)^{2}}{E_{i}}
$$

Keterangan:

$\mathrm{X}^{2} \quad$ : nilai chi kuadrat

$\mathrm{O}_{\mathrm{i}} \quad$ : nilai yang diamati

$\mathrm{E}_{\mathrm{i}} \quad$ : nilai yang diharapkan

Pengujian hipotesis dilakukan dengan menggunakan paired t-test dengan taraf signifikan 0,05 . Hipotesis dirumuskan dalam bentuk hipotesis statistik sebagai berikut:

$\mathrm{H}_{0}: \mu_{1}>\mu_{2}>$ Kemampuan berpikir kritis peserta didik dengan menggunakan media e-learning Edmodo meningkat secara tidak signifikan.

$\mathrm{H}_{\mathrm{a}}: \mu_{1}<\mu_{2}>$ Kemampuan berpikir kritis peserta didik dengan menggunakan media belajar e-learning Edmodo meningkat secara signifikan.

Pendekatan statistik uji hipotesis menurut Sugiyono (2018), dapat dihitung dengan persamaan uji pihak kiri berikut:
Keterangan:

$$
t=\frac{\bar{X}_{1}-\overline{X_{2}}}{\sqrt{\frac{S_{1}^{2}}{N_{1}}+\frac{S^{2} 2}{N_{2}}}}
$$

$\bar{X}_{1} \quad$ : nilai rata-rata pretest

$\bar{X}_{2} \quad$ : nilai rata-rata posttest

$S^{2}{ }_{1} \quad$ : varians data pretest

$S^{2}{ }_{1} \quad$ : varians data posttest

$N_{1} \quad$ : jumlah peserta pretest

$N_{2} \quad$ : jumlah peserta posttest

\section{HASIL DAN PEMBAHASAN}

Data hasil tes kemampuan berpikir kritis peserta didik dapat dilihat pada tabel berikut:

Tabel 1 Hasil Tes Kemampuan Berpikir Kritis Peserta Didik

\begin{tabular}{|l|c|c|}
\hline $\begin{array}{l}\text { Parameter } \\
\text { Statistik }\end{array}$ & Pretest & Posttest \\
\hline $\begin{array}{l}\text { Jumlah } \\
\text { peserta didik }\end{array}$ & 21 & 21 \\
\hline $\begin{array}{l}\text { Skor } \\
\text { minimum }\end{array}$ & 29 & 43 \\
\hline $\begin{array}{l}\text { Skor } \\
\text { maksimum }\end{array}$ & 57 & 86 \\
\hline $\begin{array}{l}\text { Nilai rata- } \\
\text { rata kelas }\end{array}$ & 43 & 74 \\
\hline
\end{tabular}

Peningkatan kemampuan berpikir kritis peserta didik berdasarkan uji $\mathrm{N}$ Gain, diperoleh data bahwa kemampuan berpikir kritis peserta didik sesudah penggunaan media Edmodo mengalami peningkatan dalam kategori sedang dengan nilai rata-rata $\mathrm{N}$-Gain 0,55 . Peningkatan ketercapaian indikator kemampuan berpikir kritis memiliki NGain yang berbeda-beda seperti yang terlihat pada gambar berikut: 
e-ISSN: 2721-9038

p-ISSN: 2721-902X

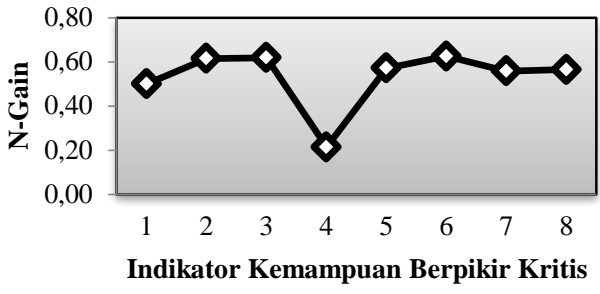

Gambar 3

Peningkatan ketercapaian indikator kemampuan berpikir kritis

Keterangan gambar:

1: Memfokuskan pertanyaan

2: Menganalisis argumen

3: Menjawab pertanyaan tentang suatu penjelasan

4: Mempertimbangkan apakah sumber dapat dipercaya

5: Mengamati dan mempertimbangkan suatu laporan hasil observasi

6: Menentukan tindakan

7: Mendeduksi dan mempertimbangkan hasil deduksi

8:Menginduksi dan mempertimbangkan hasil induksi.

Ketercapaian

indikator

kemampuan berpikir kritis peserta didik sesudah penerapan pembelajaran menggunakan Edmodo mengalami peningkatan kategori sedang pada enam indikator, namun mengalami peningkatan yang rendah pada satu indikator yaitu kemampuan mempertimbangkan apakah sumber dapat dipercaya. Rendahnya nilai $\mathrm{N}$ Gain pada kemampuan untuk memilih sumber terpercaya disebabkan oleh fitur pencarian pada Edmodo tidak terhubung secara otomatis pada situs pencarian global, sehingga sumber belajarnya terbatas pada informasi yang disediakan oleh Edmodo ataupun sumber lain yang ditautkan oleh pengguna Edmodo. Temuan yang sama juga diperoleh dari hasil penelitian Kalinggoru, dkk (2018), dimana ketercapaian indikator memilih sumber terpercaya lebih rendah dibandingkan dengan ketercapaian indikator lainnya.

Berdasarkan hasil penelitian ini diperoleh data peningkatan kemampuan berpikir kritis peserta didik secara khusus pada materi asam/basa dengan menggunakan media e-learning yaitu Edmodo. Pembelajaran diterapkan dengan memanfaatkan fitur-fitur yang tersedia pada aplikasi Edmodo. Edmodo dapat mendukung penyampaian materi pembelajaran yang perlu divisualisasikan. Selain itu, aplikasi ini juga dapat difungsikan sebagai asesmen kinerja produk yang menyediakan fitur pendukung asesmen serta memudahkan untuk mengukur kemampuan berpikir kritis serta keterampilan berkomunikasi (Kudari, 2017). Penelitian sebelumnya telah dilakukan oleh Dwiharja (2015) dengan hasil penelitian menyatakan bahwa pembelajaran menggunakan Edmodo dapat bermanfaat untuk melatih peserta didik untuk memiliki rasa tanggung jawab, melatih kemandirian, mampu memecahkan masalah, lebih kreatif, percaya diri, serta meningkatkan kemampuan berpikir kritis.

Berdasarkan pengujian hipotesis, diperoleh nilai mutlak $\mathrm{t}$ hitung adalah 10,41 dan t tabel adalah 1,73. Dengan demikian, dapat disimpulkan bahwa $\mathrm{H}_{0}$ ditolak dan $\mathrm{H}_{\mathrm{a}}$ diterima. Artinya kemampuan berpikir kritis peserta didik dengan menggunakan media e-learning Edmodo mengalami peningkatan yang signifikan. Temuan ini sesuai dengan penelitian yang telah dilakukan oleh Suparya (2020), dimana motivasi dan kemampuan berpikir kritis mahapeserta didik mengalami peningkatan setelah pembelajaran berbantuan media Edmodo.

\section{KESIMPULAN}

Kesimpulan akhir dari penelitian penggunaan media e-learning Edmodo untuk meningkatkan kemampuan berpikir kritis peserta didik adalah 
e-ISSN: 2721-9038

p-ISSN: 2721-902X

Kemampuan berpikir kritis peserta didik meningkat secara signifikan setelah penerapan pembelajaran menggunakan Edmodo. Hal ini dapat diketahui dari nilai $\mathrm{N}$-Gain rata-rata 0,55 "kategori sedang" dan peningkatan signifikan secara statistik pada pengujian hipotesis (terima $\mathrm{H}_{\mathrm{a}}$ ).

\section{UCAPAN TERIMA KASIH}

Terima kasih kepada staf kemahapeserta didikan fakultas keguruan dan ilmu pendidikan Universitas Samudra yang telah memfasilitasi administrasi dalam pelaksanaan penelitian ini. Kepada ibu dosen pembimbing 1 dan pembimbing 2 yang telah mengarahkan penulis dalam pelaksanaan penelitian. Serta kepada Guru dan Peserta Didik SMA Negeri 4 Langsa yang telah bersedia menjadi objek dan sumber informasi dalam penelitian ini.

\section{DAFTAR PUSTAKA}

Agatha, M. (2020). Penerapan eLearning dengan Platform Edmodo Untuk Meningkatkan Hasil Belajar Mahapeserta didik. Jurnal Komunikasi Pendidikan, 4(1). Hal: 1-8.

Alwan, M. (2017). Pengembangan Model blended learning Menggunakan Aplikasi Edmodo untuk Mata Pelajaran Geografi SMA . Jurnal Inovasi Teknologi Pendidikan, 4(1). Hal: 65-76.

Dwiharja, L. M. (2015). Memanfaatkan Edmodo Sebagai Media Pembelajaran Akuntansi . In Prosiding Seminar Nasional, 9(1). Hal: 332-344.

Ekayati, R. (2018). Implementasi Metode Blended Learning Berbasis
Aplikasi Edmodo. Edutech: Jurnal Ilmu Pendidikan dan Ilmu Sosial, 4(2). Hal: 148-165.

Fajiyusni, J. (2017). Deskripsi

Keterampilan Berpikir Kritis Peserta didik pada Materi Minyak Bumi Kelas XI MIA 3. Jurnal Pendidikan Kimia FKIP UNTAN, 1(1). Hal: 1-11.

Hendriana H. (2017). Hard Skill dan Soft Skill Matematika Peserta didik. Bandung : PT. Rafika Aditama.

Kalinggoru, D., dkk. (2018). Pembelajaran e-learning Berbasis Edmodo dengan Pendekatan Contextual Teaching and Learning Terhadap Kemampuan Berpikir Kritis Peserta Didik. Jurnal Santiaji Pendidikan (JSP), 8(1). Hal: 28-36.

Karimah, S., Utami, R., Hidayah, N. (2018). Keefektifan Media Pembelajaran Berbasis EdmodoTerhadap Kreativitas Mahapeserta didik. Jurnal Pendidikan Edutama,5(2). Hal: 97-101.

Kudari, L. Y. A. (2017). Pengembangan Asesmen Kinerja Produk Berbasis Edmodo untuk Mengukur Keterampilan Berpikir Kritis Peserta didik Tentang Pencemaran Lingkungan (Doctoral Dissertation, Universitas Pendidikan Indonesia).

Lestari, K. 2017. Penelitian Pendidikan Matematika. Bandung : PT Rafika Aditama.

Nuzul, D. (2019). Analisis Kemampuan Berpikir Kritis Peserta didik dalam Pembelajaran Biologi. Florea, 6(1). Hal: 45-55.

Rebeca, E. (2020). Pengembangan Alat 
e-ISSN: 2721-9038

p-ISSN: 2721-902X

Evaluasi Pembelajaran Model Flipped Classroom Berbantuan Learning Management System Edmodo Pada Materi Sistem Perkembangbiakan Tumbuhan dan Hewan Kelas Ix Smp. Universitas Sanata Dharma: Yogyakarta.

Rohman, M. (2018). Pengembangan Media Pembelajaran pada Kompetensi Dasar Jasa Bank Lainnya Berbantuan Edmodo untuk Peserta didik Kelas X SMK Koperasi Yogyakarta. Universitas Negeri Yogyakarta: Yogyakarta.

Sugiyono. (2018). Metode Penelitian Analisis Kualitatif Dan Kuantitatif $R \& D$. Alfabeta : Bandung.

Suparya, K. (2020). Peningkatan Motivasi dan Kemampuan Berpikir Kritis Mahapeserta didik Melalui Model Pembelajaran Berbasis Masalah Berbantuan Media Edmodo. Jurnal Ilmiah Pendidikan Citra Bakti, 7(1). Hal: 1-12.

Wicaksana, E. J., dkk. (2020). elearning Edmodo dengan Model PBL untuk Meningkatkan Minat Belajar Peserta didik pada Masa Pandemi Covid-19. Jurnal Pendidikan Biologi (JPB), 12(1). Hal: 22-29.

Wibowo, N.P. (2019). Pengaruh Pembelajaran Blended Learning Menggunakan Aplikasi Edmodo Terhadap Hasil Belajar dan Keterlibatan Peserta didik Pada Pokok Bahasan Mata dan Kaca Mata untuk Peserta didik kelas XI MIPA 2 SMA N 1 Ngemplak. Skripsi Program Studi Fisika Fakultas Keguruan dan Ilmu Pendidikan, Universitas Santana Dharma Yogyakarta.
Yuniarti, N. E., Ifadah, M. (2018). Keefektifan Penggunaan Aplika si Edmodo Dalam Pembelajaran Bahasa Inggris Berbasis Online Di Kelas X MIPA 6 SMA Negeri 9 Semarang. InProsiding Seminar Mahapeserta didik UNIMUS, 1(1). Hal: 460-464.

Zainudin \& Pambudi. (2019). Efektifitas Penerapan Perangkat Pembelajaran Fisika Dasar Berbasis Keterampilan Berpikir Kritis Menggunakan Aplikasi Edmodo Berplatform Android. Jurnal Pengkajian Ilmu dan Pembelajaran Matematika Dan Ipa Ikip Mataram, 7(1). Hal: 1726.

Zakiah, L. (2019). Berpikir Kritis dalam Proses Pembelajaran. Erzatama Karya Abadi: Bogor. 